Polymer Journal, Vol. 3, No. 6, pp 663-669 (1972)

\title{
Studies on Monomer Sequences in Polyesters Having Asymmetric Monomers
}

\author{
Masao Murano \\ Katata Research Institute, Toyobo Company Ltd. \\ Katata, Otsu, Japan. \\ (Received October 4, 1971)
}

\begin{abstract}
NMR spectra of homopolyesters containing asymmetric monomers, which were obtained by ordinary molten-state polycondensation under reduced pressure, are studied.

Poly(propylene terephthalate), poly(propylene malonate), poly(propylene succinate), poly(ethylene itaconate), and poly(ethylene methylsuccinate), which have asymmetric glycols or acids, show three peaks in NMR spectra of acid or glycol protons, respectively, which correspond to head to head, head to tail, and tail to tail linkages.

Binary copolyesters containing asymmetric monomers, such as poly(propylene terephthalate-succinate), have four kinds of dimeric sequences as acid units and the direction of addition of glycol unit to acid group can be detected by NMR spectroscopy.

KEY WORDS Monomer Sequence / NMR / Polyester / Asymmetric Monomer / Head to Head / Head to Tail / Poly(propyleneterephthalate) / Poly(propylene terephthalate-succinate) /
\end{abstract}

Monomer sequences and sequence distributions of many kinds of copolymers have been elucidated by high-resolution NMR. The authors $^{1}$ studied the sequence distributions of many kinds of copolyesters prepared by ordinary molten-state polycondensation from ethylene glycol and dimethyl esters of dicarboxylic acids. The trans-esterification reaction between two kinds of homopolyesters was also studied and it was found that random copolyesters were obtained. The sequence distributions of terpolyesters were also studied by $\mathrm{NMR}^{2}$ and monomer sequences of various kinds of condensation copolymers were elucidated. ${ }^{3}$

Proton absorptions of the glycol units were found to be affected by the linking acid groups and three kind of linkages in binary copolymers, $\mathrm{A}-\mathrm{G}-\mathrm{A}, \quad \mathrm{A}-\mathrm{G}-\mathrm{B}$ (or $\mathrm{B}-\mathrm{G}-\mathrm{A}$ ), and $\mathbf{B}-\mathbf{G}-\mathbf{B}$, where $\mathbf{A}$ and $\mathbf{B}$ represent acid groups and $\mathrm{G}$ glycol units, were distinguished.

In the present paper, monomer sequences of binary copolyesters containing asymmetric glycols were studied by NMR spectroscopy, and $A-G-B$ and $B-G-A$ linkages were distinguised and four linkages were found. In homopolymers containing asymmetric glycols or acids, three kinds of linkages were detected in NMR spectra.

\section{EXPERIMENTAL}

The polyesters used in the experiment were as follows:

poly(propylene terephthalate), PPT,<smiles>[CH]OC(=O)c1ccc(C(=O)OCC(C)O[V])cc1</smiles>

poly(propylene malonate), PPM,<smiles>[3H]OC(=O)CC(C)O[3H]</smiles>

poly(propylene succinate), $\mathrm{PPSu}$,<smiles>COC(=O)CCC(=O)O[Co]</smiles>

poly(ethylene itaconate), PEIT,<smiles>[3H]OCCOC(=O)C(=C)CC(=O)O</smiles>

poly(ethylene methylsuccinate), PEMS,<smiles>[CH]OCCOC(=O)C(C)CC(=O)O[Na]</smiles> 
poly(propylene phenylsuccinate), $\operatorname{PP} \phi \mathrm{S}$,<smiles>CC(=O)CC(C)OC(=O)C(C)c1ccccc1</smiles>

poly(propylene terephthalate/succinate), PPT/Su.

These polymers were prepared from glycols and dimethyl esters of the acids by ordinary moltenstate polycondensation under reduced pressure.

Dimethyl terephthalate, dimethyl malonate and dimethyl succinate were reacted with isobutyl alcohol or sec-butyl alcohol in order to make assignments for the terephthalate, or succinate protons in the corresponding polymers.

Ethylene glycol was also reacted with 2-methyl butyric acid or 3-methyl butyric acid in order to assign the ethylene glycol protons in PEMS.

The NMR spectra were measured in deuterochloroform solutions $(0.05 \mathrm{~g} / \mathrm{ml})$ at $80^{\circ} \mathrm{C}$ with Varian A-60 and HA-100 spectrometers. The spin decoupling experiment was performed by the side band method.

\section{RESULTS AND DISCUSSION}

The NMR spectrum of PPT is shown in Figure 1. The aromatic protons have three resonance peaks at $1.96,1.97$, and $1.98 \mathrm{ppm}$. These three peaks should be derived from the direction of the adjacent glycols. The effect of end groups can be neglected, because the polymer has a high enough molecular weight. Therefore these peaks are assigned to the following three structures.<smiles>CCC(C)OC(=O)c1ccc(C(=O)OCC(C)C)cc1C(=O)OCC(C)C(=O)c1ccc(C(=O)OCC(C)C)cc1</smiles>

sec-Butyl alcohol was reacted with dimethyl terephthalate to determine the chemical shifts of aromatic protons in structure (III), and isobutyl alcohol was also reacted with dimethyl terephthalate to get structure (I).

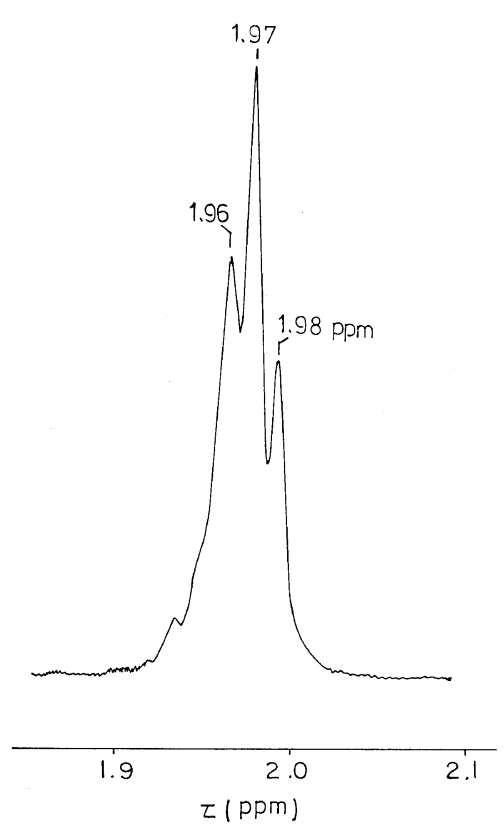

Figure 1. Aromatic proton NMR spectrum of PPT; $100 \mathrm{MHz} ; 80^{\circ} \mathrm{C}$ in $\mathrm{CDCl}_{3}$.

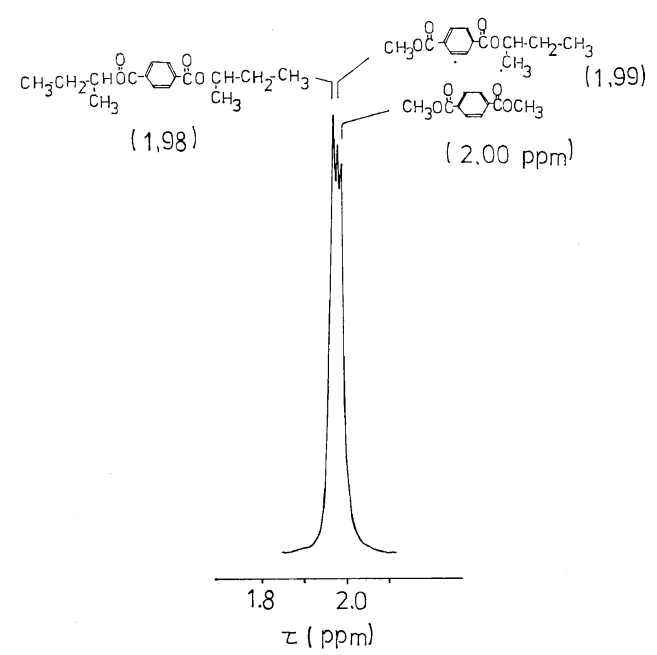

Figure 2. Aromatic proton NMR spectrum of reaction products between dimethyl terephthalate and sec-butyl alcohol; $60 \mathrm{MHz} 80^{\circ} \mathrm{C}$ in $\mathrm{CDCl}_{3}$.

As shown in Figure 2, the aromatic proton signals of the reaction products between sec-butyl alcohol and dimethyl terephthalate split into three peaks, which must be derived from unreacted dimethyl terephthalate, $\mathrm{CH}_{3} \mathrm{OOC}-\langle-$ 
$\mathrm{COO} \cdot \mathrm{CH} \cdot \mathrm{CH}_{2} \cdot \mathrm{CH}_{3}$, and $\mathrm{CH}_{3} \cdot \mathrm{CH}_{2} \cdot \mathrm{CH}-\mathrm{OOC}-$ $\stackrel{\mathrm{C}}{\mathrm{C}} \mathrm{H}_{3}$ $\stackrel{\mathrm{C}}{\mathrm{C}} \mathrm{H}_{3}$

<- $\underset{\mathrm{CH}_{3}}{\mathrm{CH}} \cdot \mathrm{CH}_{2} \cdot \mathrm{CH}_{3}$. The higher field

peak became weaker and the lower field peak became stronger as the reaction proceeded, and the higher field peak had the same chemical shifts as that in dimethyl terephthalate. Thus the higher field peak is assigned to dimethyl terephthalate and that of the lower field to

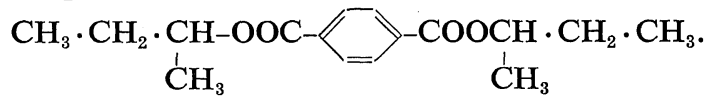
Similar assignment was made on the reaction products between isobutyl alcohol and dimethyl terephthalate, and $\mathrm{CH}_{3}-\mathrm{CH}-\mathrm{CH}_{2}-\mathrm{OOC}-\langle-$ COO- $\mathrm{CH}_{2}-\mathrm{CH}-\mathrm{CH}_{3}$ is assigned to the lowere $\stackrel{\mathrm{C}}{\mathrm{C}} \mathrm{H}_{3}$

field peak (Figure 3). The chemical shifts of the aromatic protons in $\mathrm{CH}_{3} \cdot \mathrm{CH}_{2} \cdot \mathrm{CH}-\mathrm{OOC}-\mathrm{CH}_{\mathrm{C}}$ $\mathrm{COOCH} \cdot \mathrm{CH}_{2} \cdot \mathrm{CH}_{3}$ (1.98) were found in a higher $\stackrel{\mathrm{C}}{\mathrm{C}} \mathrm{H}_{3}$

field than that in $\mathrm{CH}_{3}-\mathrm{CH}-\mathrm{CH}_{2}-\mathrm{OOC}-{ }_{\mathrm{CH}_{3}}$

COO- $\mathrm{CH}_{2} \mathrm{CH}-\mathrm{CH}_{3}$ (1.96). This may be attribut$\mathrm{CH}_{3}$

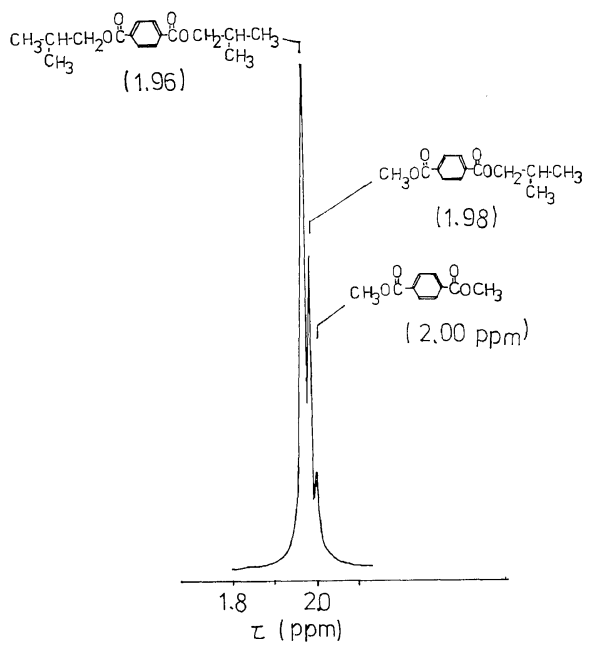

Figure 3. Aromatic proton NMR spectrum of reaction products between dimethyl terephthalate and isobutyl alcohol; $60 \mathrm{MHz}, 80^{\circ} \mathrm{C}$ in $\mathrm{CDCl}_{3}$. ed to the electron releasing effect of methyl groups. From the results on these model compounds, the three peaks of the aromatic protons in PPT are assigned to (I), (II), and (III) structures from the lower field. Although the reactivity of the secondary alcohol was rather small, structures (II) and (III) were found in considerable amounts.

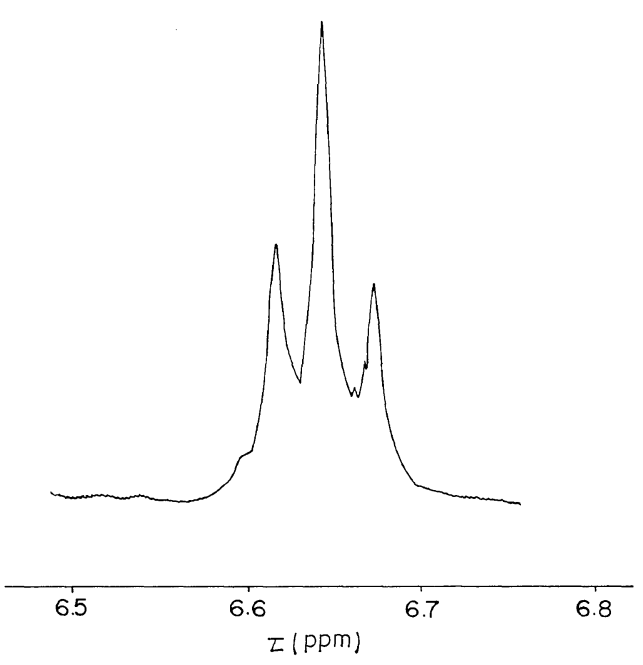

Figure 4. Methylene proton NMR spectrum of PPM; $100 \mathrm{MHz} ; 80^{\circ} \mathrm{C}$ in $\mathrm{CDCl}_{3}$.

In Fiure 4, the NMR spectrum of PPM is shown. Methylene protons in malonate gave three resonance peaks, which are derived from the following three structures.

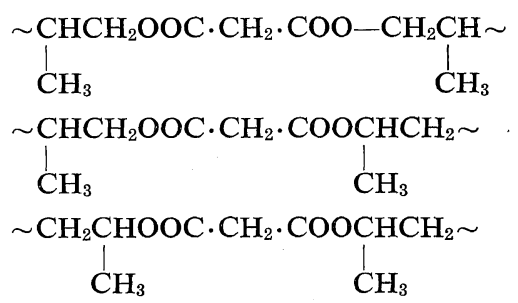

The assignments of these peaks were made by comparing with the spectra of model compounds, as in the case of PPT. The methylene protons of malonate in the reaction products of dimethyl malonate and sec-butyl alcohol were compared with those in the reaction products of dimethyl malonate and isobutyl alcohol. It was found that the former is at a higher field than the latter. Therefore the three peaks in the malonate 


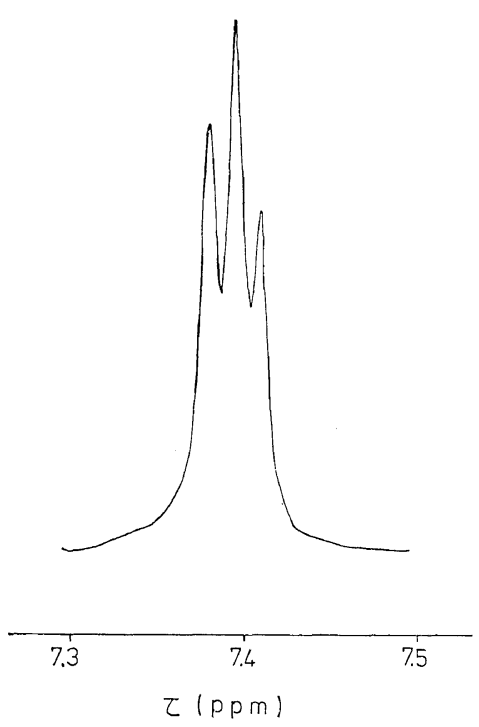

Figure 5. Ethylene proton NMR spectrum of PPSu; $100 \mathrm{MHz} ; 80^{\circ} \mathrm{C}$ in $\mathrm{CDCl}_{3}$.

methylene protons of PPM are assigned to the structures (IV), (V), and (VI) from the lower field.

The NMR spectrum of PPSu is shown in Figure 5, and the methylene proton signals in succinate split into also three peaks, which are assigned to

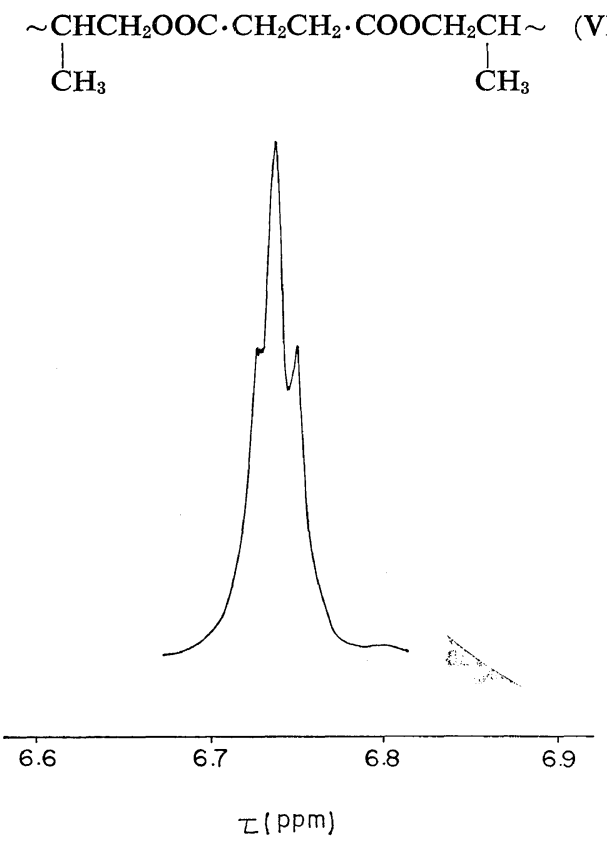

Figure 6. Ethylene proton NMR spectrum of PEMS; $100 \mathrm{MHz} ; 80^{\circ} \mathrm{C}$ in $\mathrm{CDCl}_{3}$.<smiles>CCC(C)CC(C)OC(=O)CCC(=O)OC(C)CC(=O)OCC(C)C</smiles>

from the lower field.

Three examples of monomer sequences in the polyesters which contain asymmetric glycols have been discussed. Next the monomer sequences in the polyesters which contain asymmetric acids, instead of glycols will be examined.

In Figure 6, the NMR spectrum of PEMS is shown. It is seen that the ethylene glycol proton signals split into three resonance peaks, which correspond to<smiles>CC(C)CC(=O)OCCOC(=O)CC(C)C</smiles>
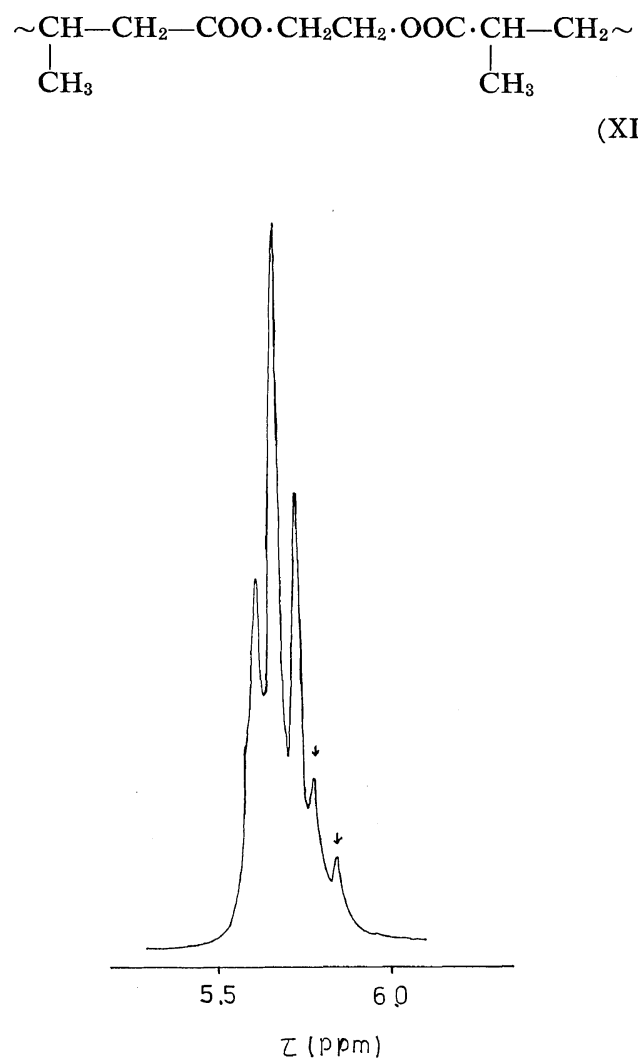

Figure 7. Ethylene proton NMR spectrum of PEIT; $100 \mathrm{MHz} ; 80^{\circ} \mathrm{C}$ in $\mathrm{CDCl}_{3}$. Peaks marked with arrows are due to end groups.

Polymer J., Vol. 3, No. 6, 1972 


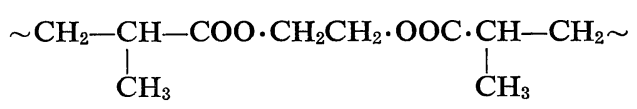

(XII)

Ethylene glycol was reacted with 2-methyl butyric acid and 3-methyl butyric acid to determine the chemical shifts of ethylene glycol protons in (XII) and (X) structures. The ethylene glycol protons in structure $(\mathrm{X})$ was found at a higher field than in (XII).

In the case of PEIT, which is shown in Figure 7, ethylene glycol protons showed quite complicated spectra. This was caused by the low-molecular-weight PEIT, because itaconate has double bonds and it is quite difficult to get high-molecular-weight samples. It was found that a PEIT with low molecular weight gave end group signals at upper fields $(5.80 \tau$ and $5.85 \tau)$. Therefore the three main peaks are assigned to<smiles>C=C(C)CC(=O)OCCOC(=O)CC(C)(CC)C(=O)OCCOC(=O)C(=C)CCOC(=O)C(=C)CC</smiles>
structures from lower field.

The NMR spectrum of $\mathrm{PP} \phi \mathrm{S}$, which was prepared from asymmetric glycol and acid, is shown in Figure 8. As can be found in the spectrum, decoupled from methine protons at about $5.00 \mathrm{ppm}$, methyl protons give four resonance peaks, which may be derived from the shielding effects of surrounding benzene rings. These four peaks may be assigned to the following four structures.<smiles>CCC(OC(=O)C(C)COC(=O)C(CC)c1ccccc1)c1ccccc1</smiles>

(XIII)<smiles>CCC(C(=O)OC(C)COC(=O)CC(C)c1ccccc1)c1ccccc1</smiles>

(XIV)<smiles>CCC(C(=O)OCC(C)OC(=O)CCc1ccccc1)c1ccccc1</smiles>

(XV)<smiles>CC(CC(=O)OCCC(C)c1ccccc1)C(=O)OCc1ccccc1</smiles>

(XVI)

Considering the effects of benzene rings, methyl protons in structure (XIII) will have the highestfield chemical shifts and the shifts will decrease in the order of (XIV), (XV) and (XVI).

So far only the direction of addition of propylene glycol to phenyl succinic acids, that is,

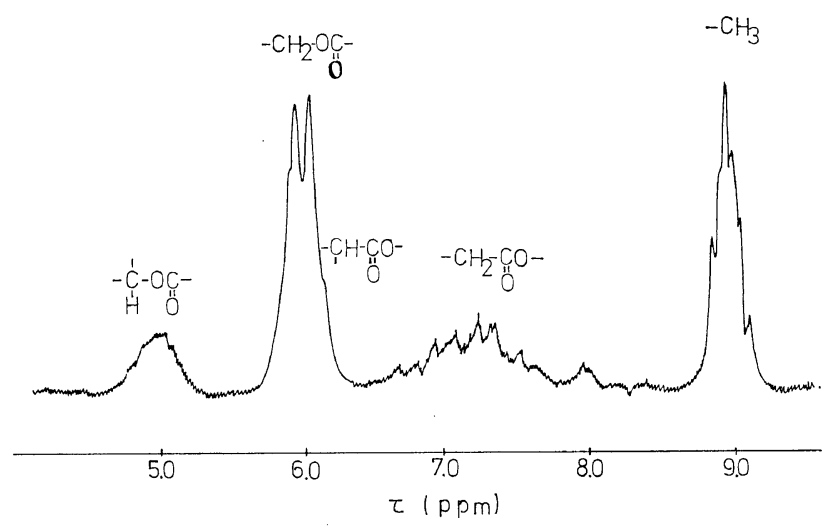

(a)

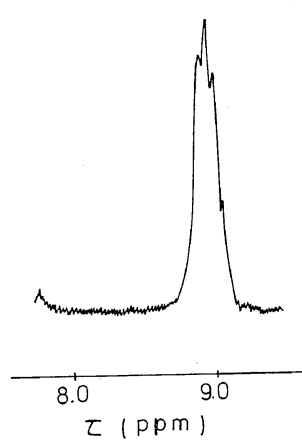

(b)

Figure 8. NMR spectrum of $\operatorname{PP} \phi \mathrm{S}$ (a), and its decoupled spectrum of methyl protons (b); $60 \mathrm{MHz}$; $150^{\circ} \mathrm{C}$ in $o$-dichlorobenzene. 


\section{Murano}

head to head, head to tail, and tail to tail linkages has been considered. The configuration of methyl and phenyl groups, that is co-isotactic ${ }^{4}$ or co-syndiotactic, was not taken into account. This seems to be quite reasonable from the recent results on the ring current effects in styrene and its copolymers. ${ }^{5}$

Next, the monomer sequences of binary copolyesters having an asymmetric glycol will be discussed. In the case of $\mathrm{PPT} / \mathrm{Su}$, the following four kinds of dimeric sequences can be suggested.

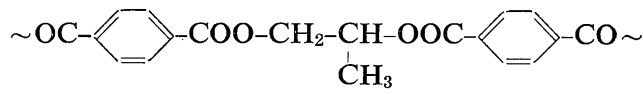

$$
\begin{aligned}
& \text { (T-P-T) }
\end{aligned}
$$

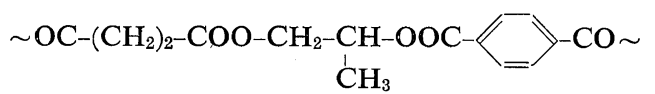

$$
\begin{aligned}
& (\mathrm{S}-\mathrm{P}-\mathrm{T})
\end{aligned}
$$

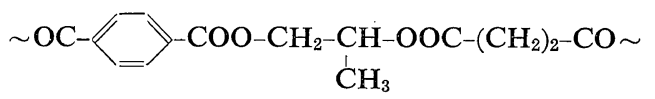

$$
\begin{aligned}
& (\mathbf{T}-\mathbf{P}-\mathbf{S}) \\
& \begin{array}{c}
\sim \mathrm{OC}-\left(\mathrm{CH}_{2}\right)_{2}-\mathrm{COO}-\mathrm{CH}_{2}-\mathrm{CH}-\mathrm{OOC}-\left(\mathrm{CH}_{2}\right)_{2}-\mathrm{CO} \sim \\
\mathrm{CH}_{3}
\end{array}
\end{aligned}
$$$$
(\mathbf{S}-\mathbf{P}-\mathbf{S})
$$

In binary copolyesters containing symmetric glycols $(G)$, such as poly(ethylene terephthalatesuccinate) copolymer, ethylene glycols in $\mathrm{T}$ G-S and $S-G-T$ have the same chemical shifts. ${ }^{1}$ But in PPT/Su, S-P-T and $\mathrm{T}-\mathrm{P}-\mathrm{S}$ linkages can be distinguished and the methyl protons have four resonance peaks as described above. Normal and decoupled spectra of methyl protons are shown in Figure 9. In Figure 9(a) methyl protons in $\mathbf{S}-\mathrm{P}-\mathrm{S}$ are just decoupled from methine protons and show single peak at $8.75 \mathrm{ppm}$ which is the same chemical shift as in PPS homopolymer, and in Figure 9(c) methyl protons in $\mathbf{T}-\mathbf{P}-\mathbf{T}$ show a single peak at $8.51 \mathrm{ppm}$, being just decoupled from methine protons, and this chemical shift is the same as in PPT homopolymer. In Figure $9(\mathbf{b})$, the two peaks at $8.61 \mathrm{ppm}$ and $8.66 \mathrm{ppm}$ seem to be decoupled from methine protons and these can be assigned to methyl protons in $\mathbf{S}-\mathbf{P}-\mathbf{T}$ and $\mathbf{T}-\mathbf{P}-\mathbf{S}$, considering the chemical shifts in $\mathbf{S}-$ $\mathbf{P}-\mathbf{S}$ and $\mathbf{T}-\mathbf{P}-\mathbf{T}$. . Therefore these four peaks
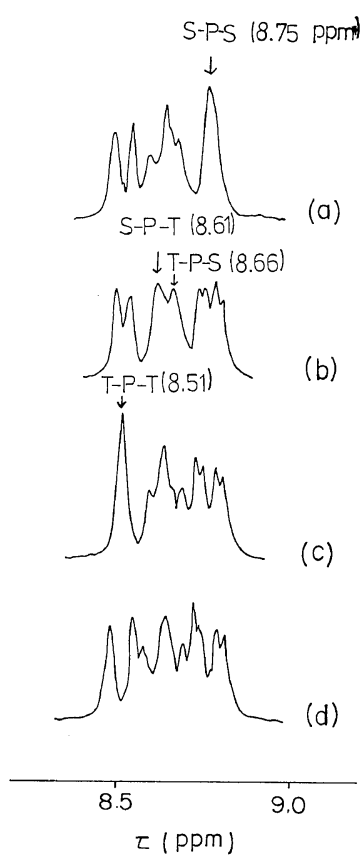

Figure 9. Decoupled methyl proton spectra of $\mathrm{PPT} / \mathrm{Su}(50 / 50)$, obtained by changing the irradiated frequency; $100 \mathrm{MHz} ; 80^{\circ} \mathrm{C}$ in $\mathrm{CDCl}_{3}$ (a) $\mathrm{CH}_{3}$ protons in $\mathrm{S}-\mathrm{P}-\mathrm{S}$ linkage $(8.75 \mathrm{ppm})$ are just decoupled from $\mathrm{CH}$ protons, (b) $\mathrm{CH}_{3}$ protons in $\mathrm{S}-\mathrm{P}-\mathrm{T}(8.61 \mathrm{ppm})$ and $\mathrm{T}-\mathrm{P}-\mathrm{S}(8.66 \mathrm{ppm})$ linkages are just decoupled from corresponding $\mathrm{CH}$ protons, (c) $\mathrm{CH}_{3}$ protons in $\mathrm{T}-\mathrm{P}-\mathrm{T}(8.51 \mathrm{ppm})$ linkage are just decoupled from $\mathrm{CH}$ protons, and (d) undecoupled.

can be assigned to $\mathrm{T}-\mathrm{P}-\mathrm{T}, \mathrm{S}-\mathrm{P}-\mathrm{T}, \mathrm{T}-\mathrm{P}-\mathrm{S}$, and $\mathbf{S}-\mathbf{P}-\mathbf{S}$ linkages from the lower field.

Thus, by NMR spectroscopy, monomer sequences in polyesters having asymmetric monomers can be elucidated and so-called head to head, head to tail, and tail to tail linkages are found in these polyesters. In binary copolymers, glycol units are affected by adjacent acid units and four linkages are found.

Acknowledgement. The author wishes to express his sincere thanks to Dr. S. Satoh of Nippon Electric Varian, Ltd., for measurement of the $100 \mathrm{MHz}$ NMR spectra. 
Monomer Sequences in Asymmetric Polyesters

\section{REFERENCES}

1. R. Yamadera and M. Murano, J. Polym. Sci., Part A-1, 5, 2259 (1967).

2. M. Murano, Polymer J., 1, 660 (1970).

3. T. Hongo, H. Suzuki, M. Murano, K. Shirasugi, and R. Yamadera, Kobunshi Kagaku, 28, 407
(1971).

4. K. Ito and Y. Yamashita, Polymer Letters, 3, 625 (1965).

5. M. Izu, N. Yamamoto, and T. Kagiya, Preprint, SPSJ 19th Symposium on Macromolecules, Kyoto, 1970, p 807. 